\title{
THE IMPACT OF NON-PARALLELISM OF TOOTHED GEAR SHAFTS AXES AND METHOD OF GEAR FIXING ON GEARBOX COMPONENTS VIBRATIONS
}

\author{
Grzegorz WOJNAR*, Michał JUZEK*
}

*Faculty of Transport, Silesian University of Technology, Krasińskiego Street 8, 40-019 Katowice, Poland

Grzegorz.Woinar@polsl.pl, Michal.Juzek@polsl.pl

received 13 September 2017, revised 28 June 2018, accepted 30 June 2018

\begin{abstract}
The subject of the experimental research was a modified back-to-back test stand. During the test, the driven gear with a number of teeth $z_{1}=16$ was fixed on stationary axis. The tested gearbox worked without load and the closing gearbox was dismantled to avoid any additional vibration and noise. A mechanical system was also used which, during the tests, allowed to change the position of the above mentioned stationary axis. Gear with number of teeth $z_{1}$ was fixed on a stationary axis with the arrangement of two self-aligning ball bearings which prevented significant changes in the angular position of axis of gear in regard of stationary axis; or fixed on a stationary axis with the arrangement of one self-aligning ball bearing which allowed significant changes in the angular position of axis of gear in regard of stationary axis. On the basis of the conducted studies, it can be stated that only in some of the analyzed cases fixing of gear with the arrangement of one self-aligning ball bearing reduces the vibration of the gearbox elements.
\end{abstract}

Key words: Toothed Gear, Non-Parallelism of Axes, Reduction, Vibration, Self-Aligning Gear Fixing

\section{INTRODUCTION}

At present, in the case of mechanical and mechatronic systems, the reduction of generated vibrations and noise is one of the main objectives (Figlus et al., 2010; Kaczynski and Hoscilo, 2017; Kaczynski et al., 2012; Li et al., 2009; Shan et al., 2005; Strassberger and Waller, 2000; Wojnar and Homik, 2015; Žul'ová et al., 2017).

Gearbox is the basic element of many drive systems used in a variety of vehicles, industrial machinery and automatic adjustment systems. As pointed out in the works (Feng and Zuo, 2012; Liang et al., 2018; Peng et al., 2018; Sawalhi and Randall, 2014; Strassberger and Waller, 2000; Wang et al., 2017; Zhou et al., 2017), vibrations signal generated by working gearboxes can be successfully used to diagnose their technical conditions or to verify and improve created models. On the other hand, the vibration and noise resulting from it greatly affect the environment and the closest surroundings of the transmission which was mentioned in (Grega et al., 2017; Łazarz, 2001; Madej, 2003; Wieczorek and Kruk, 2016). Vibroactivity of the transmission is an important topic of numerous scientific papers and experimental studies. As shown in (Åkerblom and Sellgren, 2008; Dogruer and Pirsoltan, 2017; Grega et al., 2016; Łazarz and Peruń, 2012; Razpotnik et al., 2015; Wieczorek, 2010; Wojnar, 2010), vibration and noise levels limits are searched for, among other things, in the appropriate selection of construction factors, bearing stiffness and preload, couplings, lubricant types and its operating temperatures.

The vibration level of the gearbox is influenced by the value of forces coming from the meshing of cooperating gears as well as the resonance characteristics of the individual gearbox elements such as gears, bearings and housing. In (Madej, 2003; Wilk et at., 2009) three main ways of reducing the vibration and noise emission generated by the working gearbox are indicated. These include:

- minimizing vibration in the meshing zone;

- minimizing the efficiency of vibration transmission and material sound;

- minimizing the efficiency of gearbox housing radiation.

Proper selection of couplings has significant influence on reducing the dynamic forces in the meshing and thereby reducing the force which generates vibration of the gearbox housing (Wojnar, 2010). An extremely important factor affecting the vibroactivity of the gearbox housing is its construction. The aim of the study (Figlus et al., 2010; Madej, 2003; Shen and Randall, 2008; Wilk et al., 2009) was to evaluate the impact of different types of transmission housing structure on vibration and noise emission during transmission operation. The examined housing types differed mainly in the shape of the stiffening ribs and had different stiffness, which in turn translated into various vibroacoustic characteristics of the examined solutions. As presented in (Figlus et al., 2010; Madej, 2003; Shen and Randall, 2008; Wilk et al., 2009), the appropriate choice of housing type makes it possible to significantly reduce the level of vibroactivity of the gearbox.

As already mentioned, minimizing vibration in the meshing zone is an important area in which vibration and noise reduction solutions should be searched. Undoubtedly, an important factor affecting the generated vibrations during the operation of the gearbox is the load distribution along the teeth contact line. Under real conditions, due to numerous factors, achieving an even load distribution is relatively difficult. Consequently, the cooperating teeth are most often uneven loaded across their entire width. Any uneven distribution of load along the tooth contact line contributes not only to the deterioration of durability of gearbox, but also to the increase of vibration level of operating transmission. 


\section{DESCRIPTION OF THE BACK-TO-BACK TEST STAND}

The subject of the experimental research was a modified back-to-back stand designed to test single-stage gear transmission.

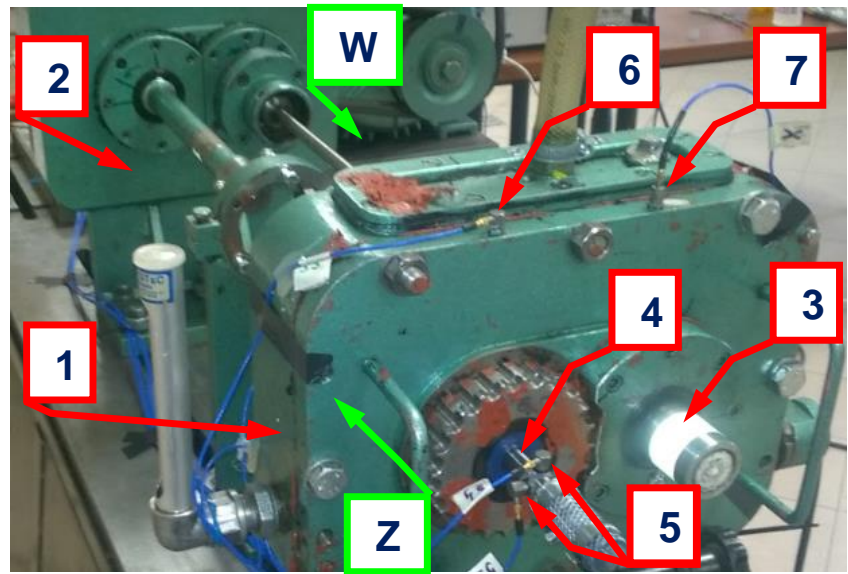

Fig. 1. Back-to-back test stand: 1 - tested geabox, 2 - closing gearbox, 3 - driving shaft, $4-$ axis of gear with a number of teeth $z_{1}=16$, 5 - vibration acceleration sensors enabling the recording of vibration acceleration of axis in the direction parallel to the peripheral force $F_{0}$ and radial force $F_{r}, 6$ - vibration acceleration sensor enabling the recording of vibration acceleration of geabox housing in the direction parallel to the peripheral force $F_{0}$ in point $K_{1}, 7-$ vibration acceleration sensor enabling the recording of vibration acceleration of geabox housing in the direction parallel to the peripheral force $F_{0}$ in point $K_{2}, Z$ - view of the test gearbox from the side lettered „Z"; W - view of the test gearbox from the side lettered "W"

The first modification of the back-to-back stand consisted of removing the gears from the closing transmission and leaving only the gears in the tested one. The purpose of this was to eliminate the noise generated by the operation of the gears in the closing transmission. The second modification of the testing stand consisted of placing a gear with straight teeth and a number of teeth $\mathrm{z}_{1}=16$ on the stationary axis and driving it through a gear with teeth number $z_{2}=24$. The gears module $m_{n}=4.5 \mathrm{~mm}$. The test gearbox worked without load. The nominal gearbox axle distance was $91.5 \mathrm{~mm}$, the meshing width was $20 \mathrm{~mm}$. The gear hub width was $35 \mathrm{~mm}$, profile shift coefficient $x_{1}=0.864$, profile shift coefficient $x_{2}=-0,5$. Gear $Z_{1}$ was made of steel $18 \mathrm{H} 2 \mathrm{~N} 2$ and Gear $z_{2}$ was made of steel $15 \mathrm{HN}$. Gearbox was made due to 6 accuracy class. The third modification consisted of the use of a mechanical system which, during the tests, allowed for a change in the position of the above mentioned stationary axis. In this way, it was possible to influence on parallelism of the gearbox axes. The mechanical system applied on one side of a pair of gearwheels marked with the letter "W" (Fig. 1) caused the bearing displacement ("W1") of a gear axis with a teeth number of $\mathrm{Z}_{1}$. The displacement resulting from applied solution was $215 \mu \mathrm{m}$ relative to its nominal position.

This displacement has resulted in an increase in gearbox axle distance relative to the nominal value of $215 \mu \mathrm{m}$ and this value in relation to the distance of the axes is in the relative measure less than 0.0025 , and in relation to the height of the tooth is less than 0.022. It should be noted here that, according to (Müller, 1996), one of the advantages of the involute gears used in the study is that there is no increase in dynamic forces in the meshing of change of gearbox axes distance (of course, while maintaining their parallelism). On the other side of the pair of gears marked with the letter "Z" (Fig.1), the mechanism allowed to move the center of the outer ring of the bearing ("Z1") in polar coordinates. The center of this polar coordinates was the original bearing axis position "Z1". Leader radius value was $r_{w Z 1}=250 \mu \mathrm{m}$ and a choice of one of 24 angular positions spaced at $15^{\circ}$ was possible. The numbering of the bearing position "Z1" given later in this article is shown in Fig. 2. For position no. 1, the angle $\varphi_{r w z 1}$ was $37.5^{\circ}$. The sign used $k_{\text {n.p. }}$ (Fig. 2) indicates the direction of the rising bearing position numbers "Z1". Changing the position of the "Z1" bearing influenced the variation of the position of the stationary axis, and by that changing the value of the axle non-parallelism.

Another modifications depend on that the gear with teeth number $\mathrm{Z}_{1}$ :

- was fixed on stationary axis using two self-aliging ball bearings arranged side by side, which prevented significant changes in the angular position of axis of gear in regard to stationary axis; this situation is designated by the letters MS;

- was fixed on stationary axis using one self-aliging ball bearings, which allowed significant changes in the angular position of axis of gear in regard of stationary axis; this situation is designated by the letters MW.

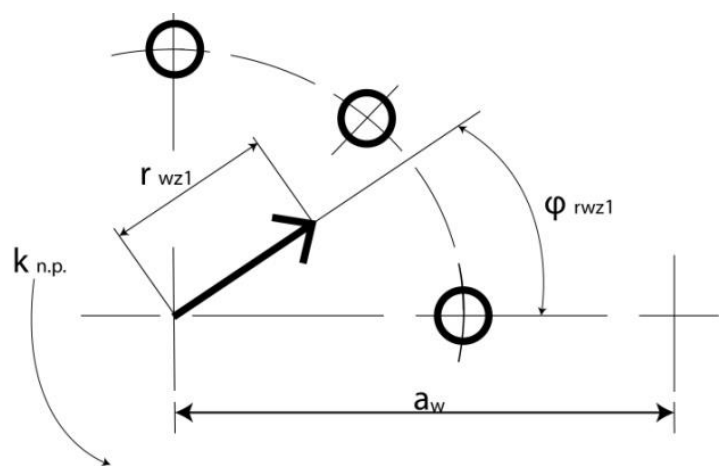

Fig. 2. Method of numbering the bearing "Z1"position; view from the side marked with the letter $Z$ in Fig. 1

During the measurements of vibration acceleration signals, piezoelectric vibration acceleration sensors were used, while for measuring the instantaneous angular velocity variations of the rotating shaft, a RLV-5500 laser vibrometer was used.

The following signs of points and directions of measurments were used:

- K1Z_FO - measurement of vibration acceleration of the transmission housing at the point $\mathrm{K} 1$ in a direction parallel to the action of the peripheral force $F_{0}$ (Fig. 1, position 6);

- K2Z_FO - measurement of vibration acceleration of the transmission housing at the point $\mathrm{K} 2$ in a direction parallel to the action of the peripheral force $F_{0}$ (Fig. 1, position 7);

- 01Z_FO - measurement of vibration acceleration of gear $z_{1}$ axis in section $01 Z$ in a direction parallel to the action of the peripheral force $F_{0}$ (Fig. 1, position 5 ); cross-section of the $01 \mathrm{Z}$ axis is located on the gearbox side from $\mathrm{Z}$ direction (Fig. 1);

- $01 Z_{-} F R$ - measurement of vibration acceleration of gear $z_{1}$ axis in section $01 \mathrm{Z}$ in a direction parallel to the action of the radial force $F_{r}$ (Fig. 1, position 5); 
- O1W_FO - measurement of vibration acceleration of gear $z_{1}$ axis in section $01 \mathrm{~W}$ in a direction parallel to the action of the peripheral force $F_{0}$; cross-section of the $01 \mathrm{~W}$ axis is located on the gearbox side from $\mathrm{W}$ direction (Fig. 1);

- 01W_FR - measurement of vibration acceleration of gear $z_{1}$ axis in section $01 \mathrm{~W}$ in a direction parallel to the action of the radial force $F_{r}$;

- $\Delta \omega \_2$ - measurement of temporary changes of the angular velocity of the shaft with gear $\mathrm{z}_{2}$.

Recorded vibration signals generated during gearbox operation at various rotational speeds of the gears were synchronously sampled at frequency $f_{p}=51.2 \mathrm{kHz}$. Time of gearbox operation was 5 hours after setup testing stand.

\section{TEST RESULTS AND THEIR ANALYSIS}

Based on the recorded vibration signals of the various transmission components, their RMS values are calculated and shown in Fig. 3 as a function of the bearing position "Z1" and the method

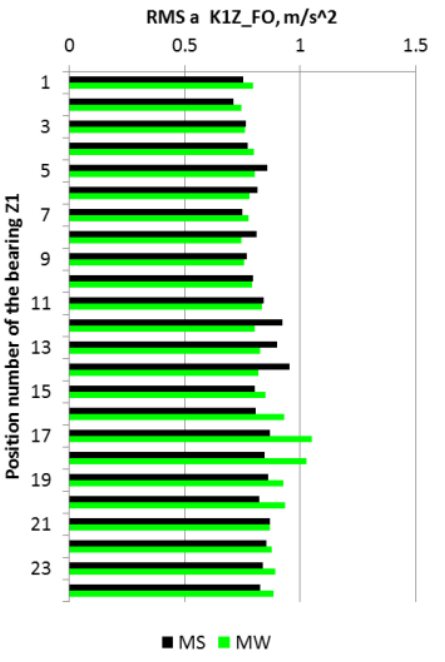
of fixing the gear $\mathrm{Z}_{1}$ on the stationary axis.
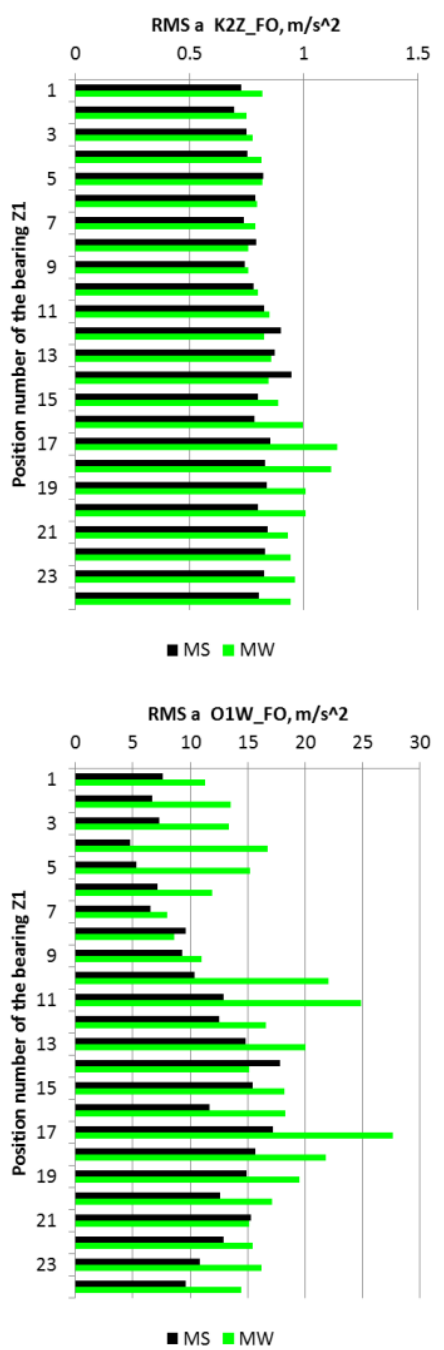
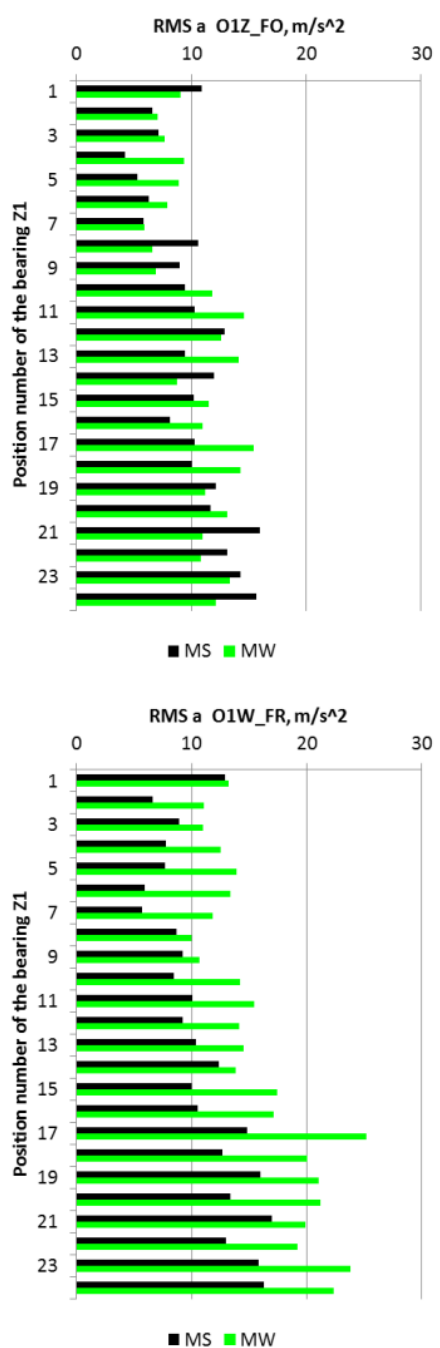
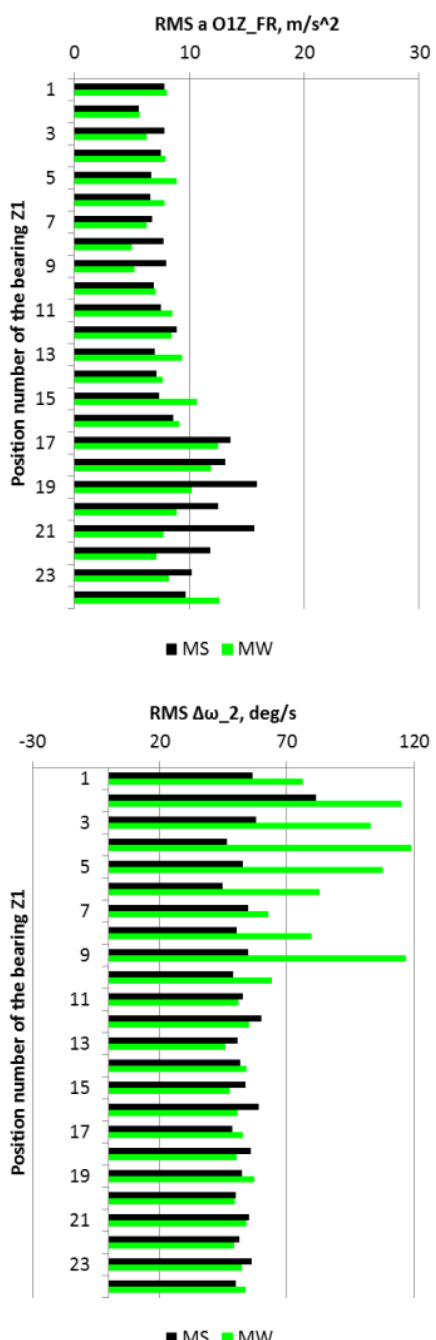

Fig. 3. The RMS values of the vibration signals of the various transmission elements shown in the function of the bearing "Z1" position (according to description in section 2 and Fig. 2) and the method of fixing the gear $z_{1}$ on the stationary axis, obtained when the tested gearbox operated with a rotational speed of the gear $z_{2}$ of $f_{02}=20 \mathrm{~Hz}$ 
In the case of test gear operation with a rotational speed of gear $\mathrm{Z}_{2}$ of $f_{02}=20 \mathrm{~Hz}$, there was no significant reduction in RMS value of vibration signals due to the change of the gear fixing method on the stationary axis (Fig. 3). On the other hand, the increase in the RMS value of the instantaneous angular velocity changes in shaft number 2 caused by the change in the gear fixing method in the case of the bearing position "Z1" was $155 \%$ (Fig. 4). In the case of the vibration signals of other transmission components, also the percentage increase in the vibration acceleration signal RMS value was often significant due to the self-aligning of the gear (Fig. 4).

In the case of vibration signals generated by gears with straight teeth, the greatest amplitude usually consists of the frequency spectrum components associated with the frequency of the meshing and its harmonics. For this reason, the frequency analysis of the recorded vibration signals has also been performed to analyze method of gear fixing on the axis and the accompanying phenomena.

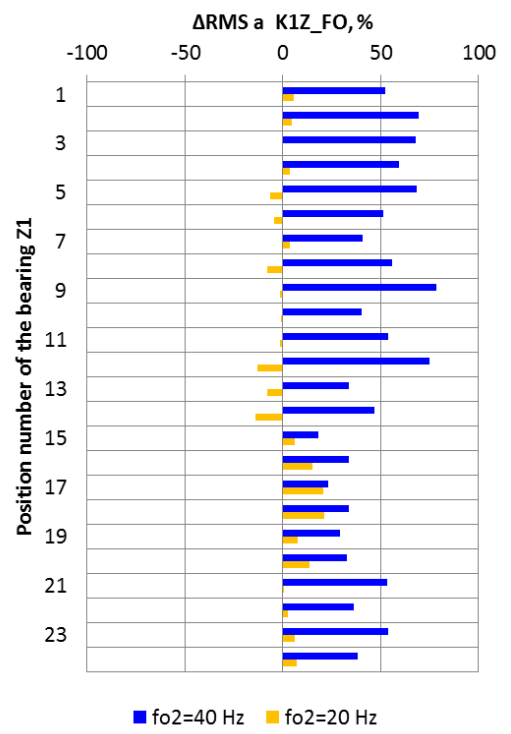

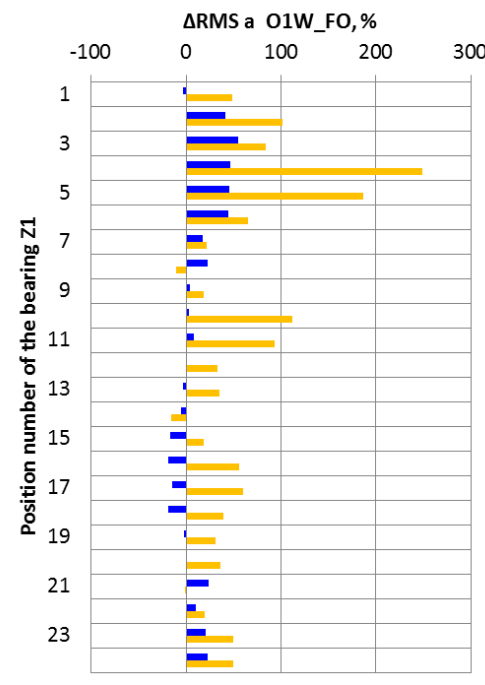

- $\mathrm{fo} 2=40 \mathrm{~Hz} \quad$ fo $2=20 \mathrm{~Hz}$

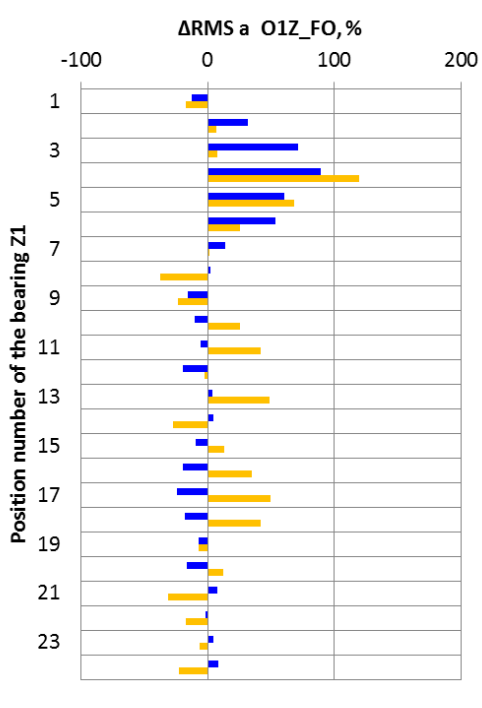

- $\mathrm{fo} 2=40 \mathrm{~Hz} \quad$ fo $2=20 \mathrm{~Hz}$

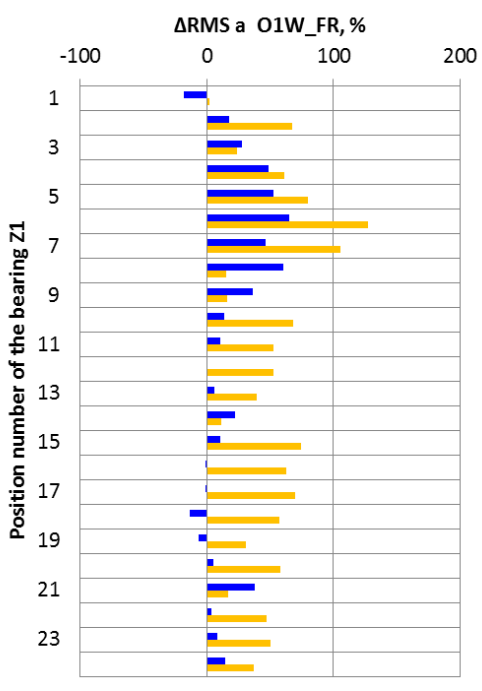

- fo $2=40 \mathrm{~Hz} \quad$ fo $2=20 \mathrm{~Hz}$
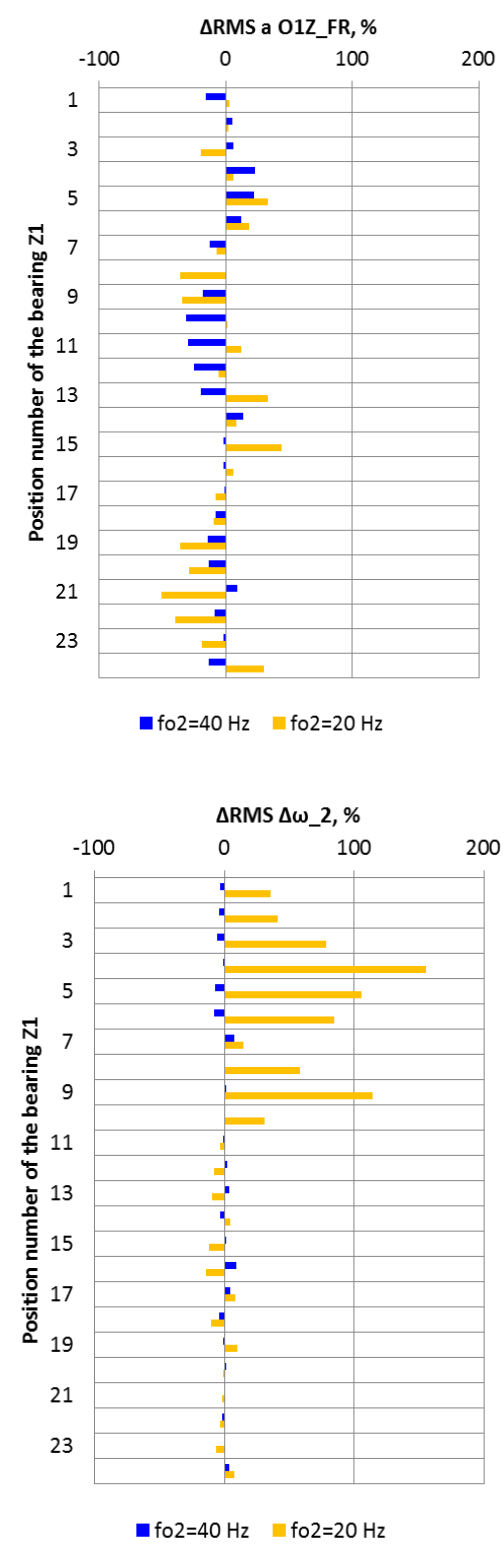

Fig. 4. Changing the RMS value of the vibration signals of the various transmission elements due to the method of fixing the gear $z_{1}$ on the stationary axis (according to description in section 2 and Fig. 2) when the tested gearbox operated with a rotational speed of the gear $\mathrm{z}_{2}$ of $f_{02}=20 \mathrm{~Hz}$ and $f_{02}=40 \mathrm{~Hz}$ 
Fig. 5 shows that in the case of gearbox operation with a rotational speed of $f_{02}=20 \mathrm{~Hz}$ and a bearing "Z1" position of no.9, the use of self-aligning gear fixing resulted in a significant reduction of amplitude in the meshing frequency $\left(f_{z}=480 \mathrm{~Hz}\right)$ at point 01Z_FR. This phenomenon was also observed for other points and vibration signals.
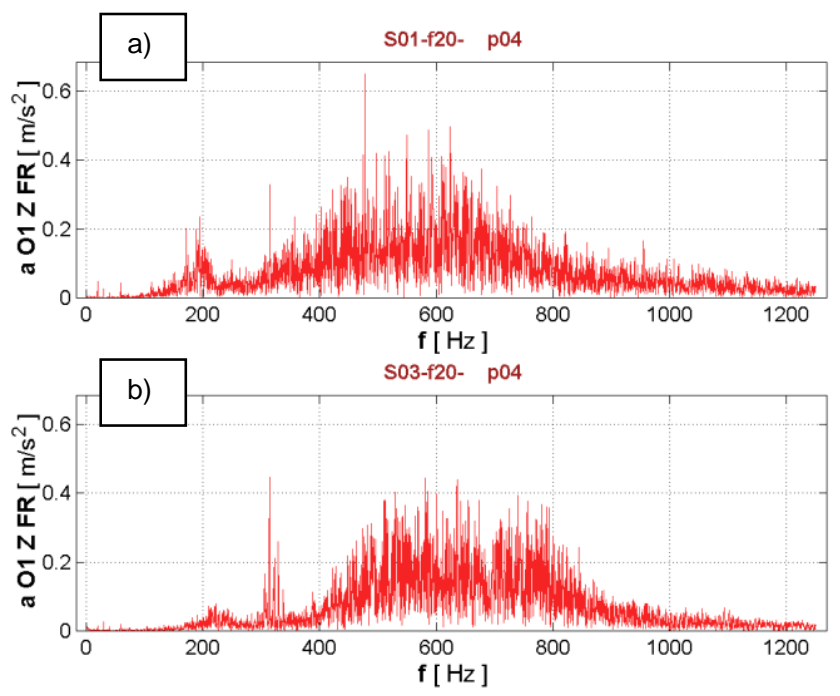

Fig. 5. Spectrum of the vibration acceleration signal of the axis registered at point 01Z_FR

a)

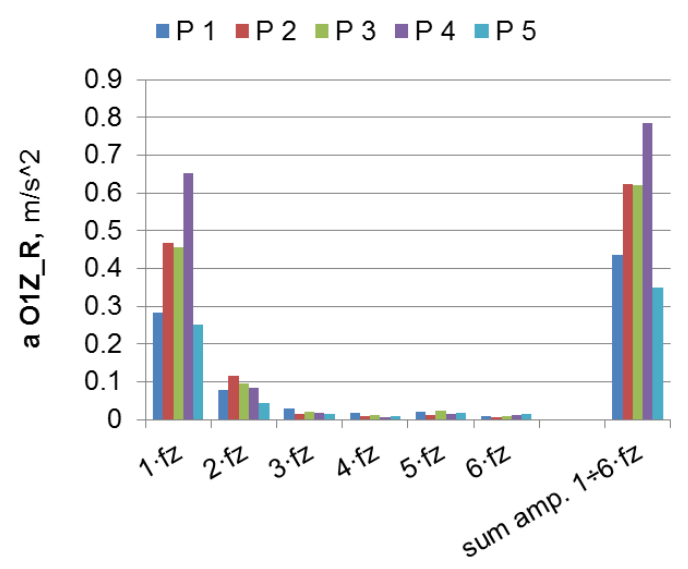

b)

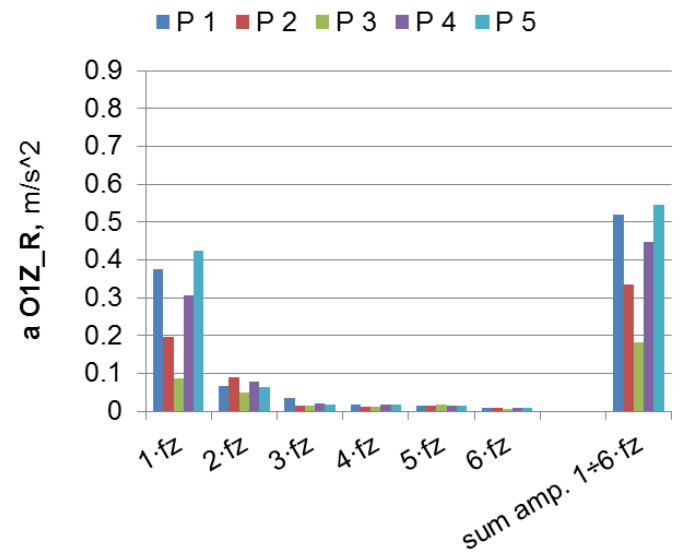

Fig. 6. Summary of amplitudes of meshing frequency $f_{z}$ and their harmonics in case of vibration acceleration singnal of gear $\mathrm{Z}_{1}$ axis registered at point 012 FR, bearing position "Z1" P1 $\div 5$ and rotation frequency $f_{02}=20 \mathrm{~Hz}$.
For the mentioned above signal and gearbox operation with different bearing "Z1" positions it can be seen that the successive harmonics of the meshing frequencies have a significantly lower amplitude than the amplitude associated with the meshing frequency (Fig. 6).

However, in case of vibration acceleration of gearbox housing (Fig. 7), dominating amplitude did not have the first harmonics of meshing frequencies but sequences harmonics no. 2, 3, 4 or 5 . Most often, the sixth harmonic frequency was significantly less amplitude.

a)

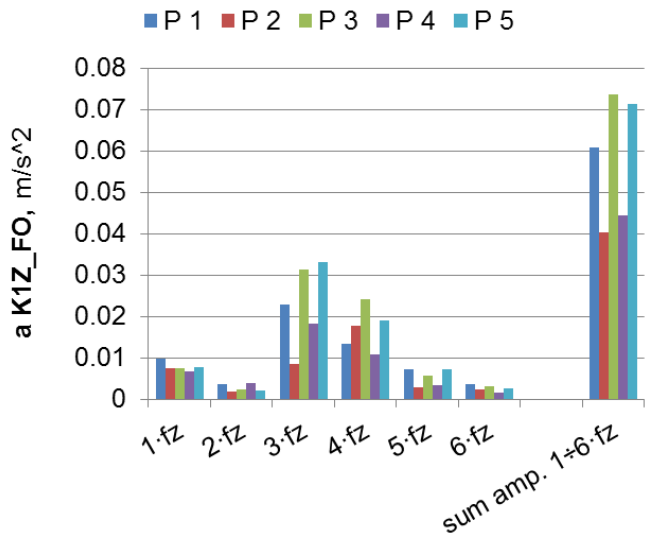

b)

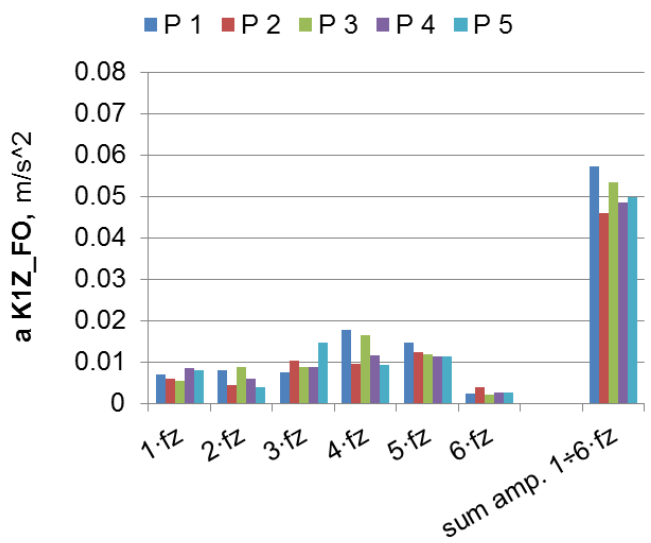

Fig. 7. Summary of amplitudes of meshing frequency $f_{z}$ and their harmonics in case of vibration acceleration singnal of gearbox housing registered at point 012 FR, bearing position "Z1" P1 $\div 5$ and rotation frequency $f_{02}=20 \mathrm{~Hz}$

Due to the fact that in the case of gearboxes, the amplitudes of the various harmonics of the meshing frequencies have a maximum value (e.g. Fig. 7) in order to analyze the effects occurring with said frequency and its harmonics, an indicator was assumed as sum of amplitudes of all 6 harmonic meshing frequencies.

On the basis of the observation of obtained results shown in Figs. 8 and 9 with different rotational frequencies, it can be concluded that in most positions of the bearings "Z1", the sum of the amplitudes of the first six harmonic of meshing frequencies of the signal of temporary variations in angular velocity of the gearbox shaft 2 is smaller when using the self-aligning fixing of gear $z_{1}$. This means that the increase in the RMS value of this signal seen in Fig. 4 is caused by the increase in amplitudes of other factors of the frequency spectrum than those associated with the meshing frequency and its harmonics.

The above-mentioned effects were also observed for other signals for which the comparison of the harmonic amplitude values of the meshing frequency is shown in Fig. 8. 

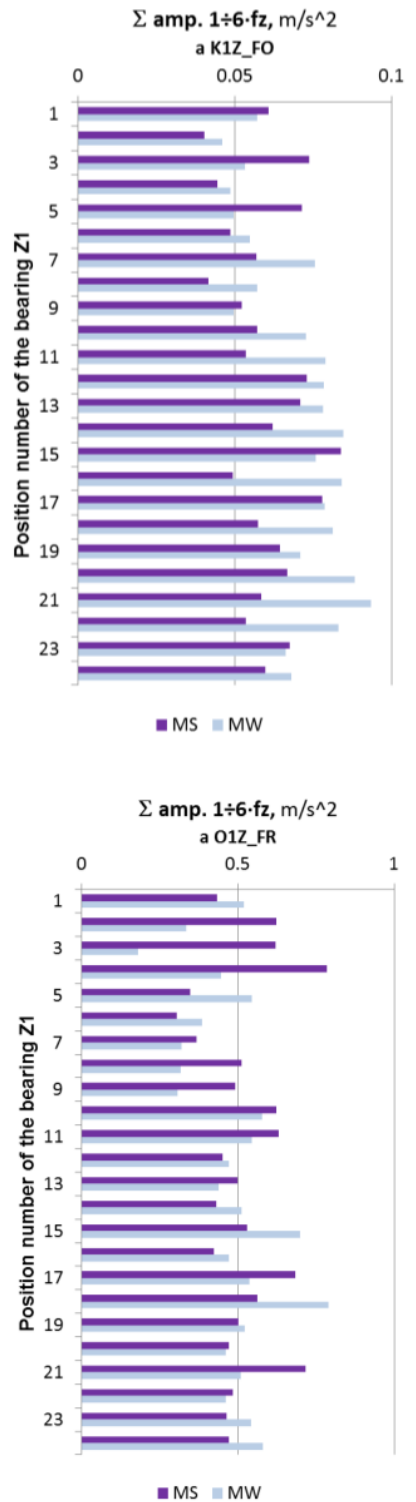

$\Sigma$ amp. $1 \div 6 \cdot f z, d e g / s$

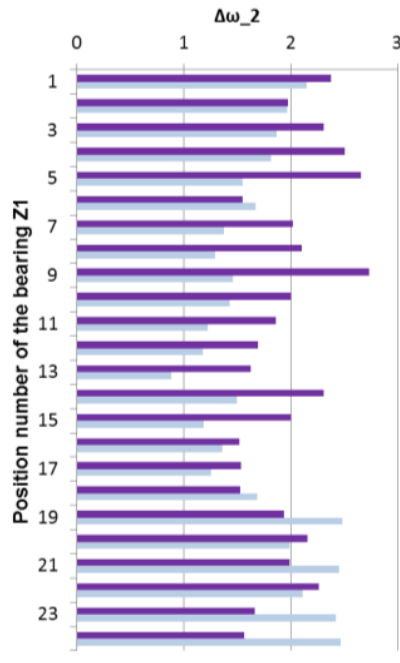

$=\mathrm{MS}=\mathrm{MW}$

Fig. 8. Sums of amplitudes of the first 6 harmonic meshing frequencies obtained from the vibration signals of the various transmission elements shown in the function of the bearing "Z1" position and the method of fixing the gear $\mathrm{Z}_{1}$ on the stationary axis, when the tested gearbox operated with a rotational speed of the gear $z_{2}$ of $f_{02}=20 \mathrm{~Hz}$
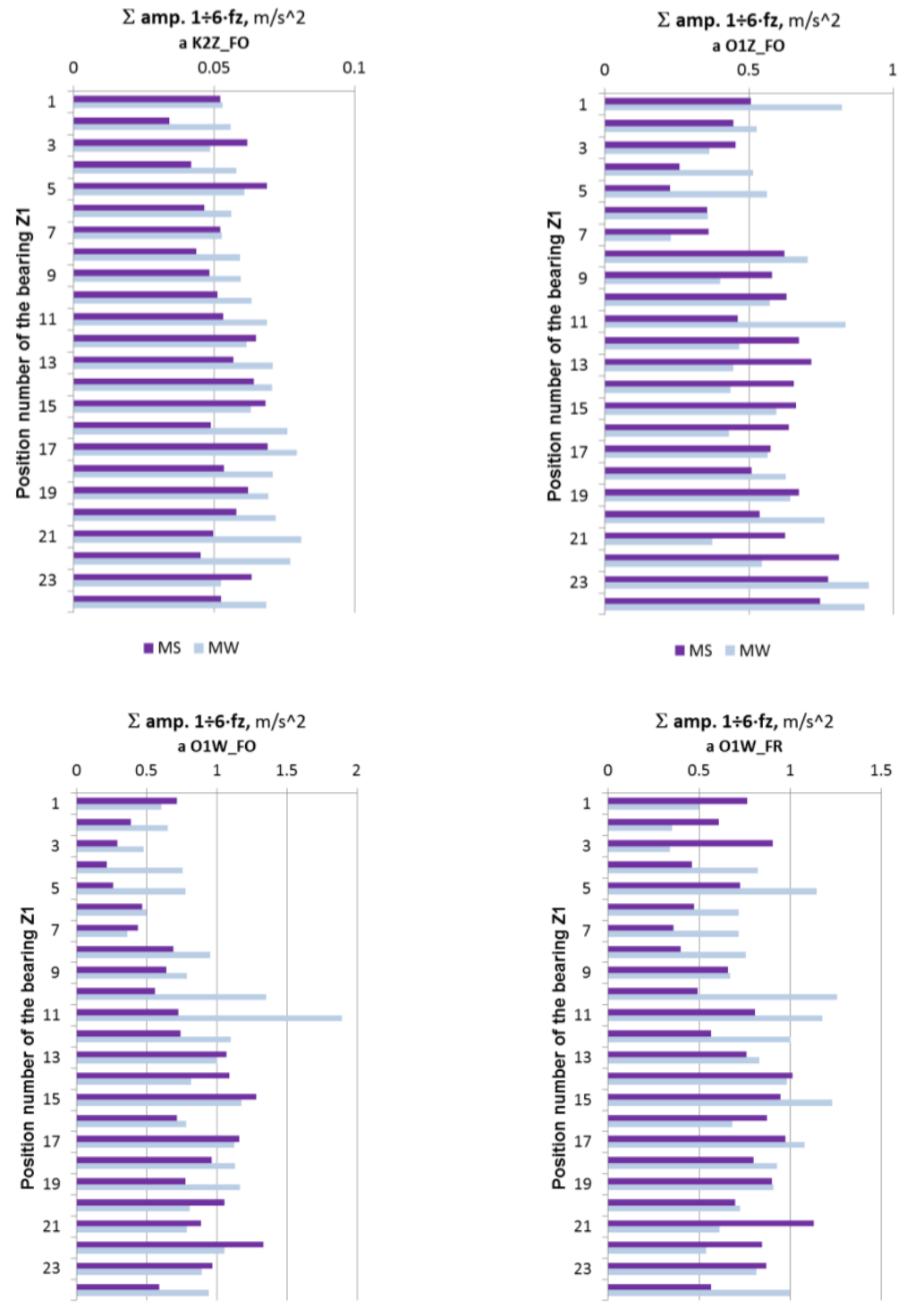

$=\mathrm{MS}=\mathrm{MW}$

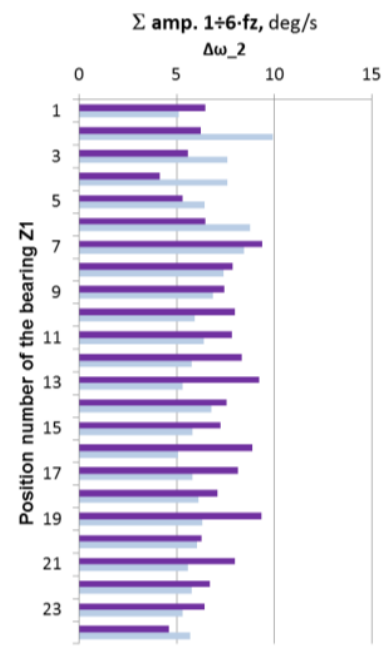

$\because \mathrm{MS}=\mathrm{MW}$

Fig. 9. Sums of amplitudes of the first 6 harmonic meshing frequencies obtained from the signals of temporary changes of the angular velocity of the shaft with gear $z_{2}$ shown in the function of the bearing "Z1" position and the method of fixing the gear $\mathrm{Z}_{1}$ on the stationary axis, when the tested gearbox operated with a rotational speed of the gear $z_{2}$ of $f_{02}=40 \mathrm{~Hz}$ 


\section{CONCLUSION}

Based on the experimental research and analysis of signals, it can be stated that:

- For gearbox characterized by relatively longer periods of unloaded operation compared to periods when gearbox works with load, it is not recommended to use the self-aligning gear fixing because, in the absence of load in a significant number of cases, the increase of the RMS value of analyzed vibration signals caused by the use of said solution is greater than the vibration reduction resulting from the application of this solution.

- The sum of the amplitudes of the first six harmonics of the temporary changes of the angular velocity of the shaft with gear $z_{1}$, in the case of a many number of bearing "Z1" positions has lower value with the self-aligning gear $z_{1}$ fixing than in the absence of it. This is important because during the operation of gearbox with spur gears, the dominant amplitude in the frequency spectrum has a frequency of meshing and its harmonic, so that the self-aligning fixing of gear can in this case offer the possibility of reducing the effects caused by non-parallelism of gearbox axes. The authors of this publication plan further research in this field.

\section{REFERENCES}

1. Åkerblom M., Sellgren U. (2008), Gearbox noise and vibration influence of bearing preload, TRITA-MMK 2008:17.

2. Dogruer C.U., Pirsoltan A.K. (2017), Active vibration control of a single-stage spur gearbox, Mechanical Systems and Signal Processing, 85, 429-444.

3. Feng Z., Zuo M.J. (2012), Vibration signal models for fault diagnosis of planetary gearboxes, Journal of Sound and Vibration, 331, 4919-4939.

4. Figlus T., Wilk A., Madej H. (2010). A study of the influence of ribs shape on the gear transmission housing vibroactivity, Transport Problems, 5 (1), 63-69.

5. Grega R., Krajňák J., Žul'ová L., Fedorko G., Molnár V. (2017), Failure analysis of driveshaft of truck body caused by vibrations, Engineering Failure Analysis, 79, 208-215.

6. Grega R., Homišin J., Krajňak J., Urbanský M. (2016), Analysis of the impact of flexible couplings on gearbox vibrations, Scientific Journal of Silesian University of Technology, Series Transport., 91, 43-50.

7. Kaczynski R., Hoscilo B. (2017): Mechanical and friction characteristics of the coating surface of the cutting tool on the basis of instrumental measurements micro-hardness and scratch-test, Friction and Wear, 38(2), 92-100.

8. Kaczyński R., Wilczewska I., Hościło B., (2012), Construction analysis of mini-generator of electric energy using working medium flow as the working environment, Key Engineering Materials, 490 $45-53$.

9. Lazarz B. (2001), Identified dynamic model of the gearbox as the basis for design (in Polish), Wydawnictwo i Zakład Poligrafii Instytutu Technologii Eksploatacji, Katowice-Radom.

10. Lazarz B., Perun G. (2012), Influence of construction factors on the vibrational activity of the gearing, Transport Problems, 7(2), 95-102.

11. Li H., Le M.D, Gong Z.M, Lin W. (2009), Motion profile design to reduce redidual vibration of high-speed positioning stages, IEEE/ASME Transactions on Mechatronics, 14(2), 264-269.
12. Liang X., Zuo M.J., Feng Z. (2018), Dynamic modeling of gearbox faults: A review, Mechanical Systems and Signal Processing, 98, 852-876.

13. Madej H. (2003), Minimization of vibroacoustic activity of gearboxes hausings (in Polish), Wydawnictwo i Zakład Poligrafii Instytutu Technologii Eksploatacji, Katowice-Radom.

14. Müller L. (1996), Gearboxes - design (in Polish), Wydawnictwa Naukowo-Techniczne, Warszawa.

15. Peng Y., Zhao N., Qiu P., Zhang M., Li W., Zhou R. (2018), An efficient model of load distribution for helical gears with modification and misalignment, Mechanism and Machine Theory, 121, 151-168.

16. Razpotnik M., Bischof T., Boltežar M. (2015), The influence of bearing stiffness on the vibration properties of statically overdetermined gearboxes, Journal of Sound and Vibration, 351, 221-235.

17. Sawalhi N., Randall R.B. (2014), Gear parameter identification in a windturbine gearbox using vibration signals, Mechanical Systems and Signal Processing, 42, 368-376.

18. Shan J., Liu H.T., Sun D. (2005), Slewing and vibration control of a single-link flexible manipulator by positive position feedback (PPF), Mechatronics, 15 (4), 487-503.

19. Shen A., Randall R.B. (2008), Optimal rib stiffening for noise reduction of constant speed gearboxes, 15th International Congress on Sound and Vibration, Korea, Daejeon, 2008.

20. Strassberger M., Waller H. (2000), Active noise reduction by structural control using piezo-electric actuators, Mechatronics, 10(8), 851-868.

21. Wang T., Chu F. Han Q., Kong Y. (2017), Compound faults detection in gearbox via ameshing resonance, Journal of Sound and Vibration, 392, 367-381.

22. Wieczorek A. (2010), The role of lubrication in reducing noise associated with the operation of gearboxes (in Polish), Mechanizacja i Automatyzacja Górnictwa, 478 (12), 34-39.

23. Wieczorek A., Kruk R. (2016), Minimization of vibroacoustic effects as a criterion for operation of gear transmissions in accordance with sustainable development principles, Management Systems in Production Engineering, 12 (1), 12-19.

24. Wilk A., Lazarz B., Madej H. (2009), Vibroactivity of gear transmissions. The influence of constructional features and wear of elements on the vibroactivity of drive systems with gear transmissions (in Polish), Wydawnictwo Naukowe Instytut Technlogii Eksploatacji, Katowice-Radom.

25. Wojnar G. (2010), Minimization of dynamic forces in gear meshing by selection of the flexible couplings parameters, Journal of Kones. Powertrain and Transport, 17 (3), 497-504.

26. Wojnar G., Homik W. (2015), Reduction of the amplitudes of selected components of the frequency spectrum of momentary velocity of the crankshaft of the internal combustion engine piston through the use of torsional vibration dampers, JVE International Conference, Katowice, Poland, October 14-15th, Vibroengineering Procedia 1, 6, 83-87.

27. Zhou L., Duan F., Corsar M. Elasha F., Mba D. (2017), A study on helicopter main gearbox planetary bearing fault diagnosis, Applied Acoustics, 127, 213-221.

28. Žul'ová L., Grega R., Krajňák J., Fedorko G., Molnár V. (2017), Optimization of noisiness of mechanical system by using a pneumatic tuner during a failure of piston machine, Engineering Failure Analysis, 79, 845-851. 